\title{
The Value-Relevance Of Internet Web Traffic And Revenue On Top Arab Banks' Comparative Efficiency Performances
}

Bruce Q. Budd, Alfaisal University, Saudi Arabia

D. B. Budd, Edith Cowan University, Australia

\begin{abstract}
The comparative efficiency performances of the top Middle East Arab banks are measured using Data Envelopment Analysis (DEA) and Principal Components Factor Analysis (PCFA). Crosssectional data are used from Bankscope and the recently constructed and publically available web metrics, Alex.com, for 2008. This paper identifies the 'best practices' of banks associated with measures of internet web traffic and revenue outputs. Results identify large disparities between Arab banks' comparative efficiency performances. The highest technically efficient scoring banks were not necessarily the larger banks and banks that were efficient were not necessarily profitable. No significant relationship was detected between large banks that are efficient at generating website visits and those that are efficient at generating revenues. Smaller banks revealed more evidence of comparative efficiency performance towards generating website traffic output. From a policy perspective, this study highlights the importance of encouraging increased efficiency throughout the banking industry in the Arab world, particularly in the area of internet banking. It further reveals the state of some electronic data availability and transparency in the MENA region.
\end{abstract}

Keywords: Data Envelopment Analysis; Principal Factor Component Analysis; web traffic

\section{INTRODUCTION}<smiles>[O]</smiles>

ver recent years, Arab banks have moved closer to western banking models. One particular development that harmonizes both worlds of the banking industry is the use of internet technologies. The internet market has grown into a highly competitive, cost saving, and therefore potentially profitable, outlet for the banking industry. Internet banking can reduce business operations' costs and decrease the distribution of branch locations. Benefits of internet banking have been well documented - better quality customer service (Owens, 2000), increased number of customers (Daniel, 2000), increased revenue (Daniel, 2000, and Auger \& Gallaugher, 2001), ability to reach a wider market (Gallaugher, 2001), cost reductions, (Owens, 2000, and Franco \& Klien, 1999). See Shah and Bokhari (2002) for further discussions.

The Arab world generally has a relatively well-developed and technologically advanced telecommunications infrastructure and has a growing mobile telephone and Internet penetration. Extending and improving the use of internet banking is now considered to be of crucial importance to the Arab banking industry. With recently available competitive intelligence data, it is now possible, for the first time, to electronically observe and empirically research the frequency of access to top Arab banks' websites in 2008.

It is against this backdrop that a series of research questions emerge concerning these banks' operational and efficiency performances. What disparities exist between top Arab banks' efficiency performances? Are large banks (by total assets) more technically efficient than smaller banks? Are banks that are profitable also efficient banks? And which banks that are efficient at generating website visits also efficient at generating revenues? 


\section{LITERATURE REVIEW}

Research in banking, in particular, is seen as an area of vital importance for future development for emerging economies, such as the Middle East. The literature on bank performance measures follow several paths DEA (Wen, 2003, and Chien-Ta Bruce, 2009a), Free Disposal Hull (FDH), Stochastic Frontier Approach (SFA, also called Econometric Approach; Berger, Hunter \& Timme, 1993), Thick Frontier Approach (TFA; Berger \& Humphrey, 1997), and the Distribution Approach (Berger et al., 1993). These approaches primarily differ in how much restriction is imposed on the specification of the best practice frontier and the assumption of random errors and inefficiency (Wu, 2006). Mostafa (2007) measures the relative efficiency of the top 100 Arab banks using cross-sectional data for the year 2005. He uses DEA and accesses data from the Middle East (2006). His paper's methodology is similar to Seiford and Zhu (1999), which researched the profitability and marketability of the top 55 US commercial banks. Similarly, research using the DEA technique on Arab countries (Saudi Arabia, Tunisia and Jordan) by Al-Faraj et al. (1993), Chaffai (1997) and Al-Shammari and Salim (1998), respectively, did not consider the value-relevance of internet banking. Liang, Lin and Chen (2004) use DEA to investigate how a firm's ecommerce performance is affected by characteristics unique to their respective industries. Their research reports that an increase in net access encourages firms to use web-based e-commerce to expand their markets. They also report that e-commerce most benefits industries with high information intensity products. Liang et al. (2004) report that industrial characteristics can affect e-commerce performance significantly and the results show that its impact on the banking industry is higher than in software, advertising and others.

Wen, Lim and Huang (2003) use DEA to evaluate the relative efficiency of 120 e-commerce sites in 2003 and use a model to help management identify inefficient operations. Wen et al. (2003) combine financial variables, operational variables and e-commerce specific variables as the input and output variables for the DEA model to measure e-commerce efficiency. Their results show that e-commerce efficiency cannot be determined only by annual sales or any single input or output measure. All key variables from financial and non-financial (operational, e-commercial specific measurement) need to be measured and analysed as they relate to each other. Other methods adopted to research online performance assessment include hierarchy process (Min, 2005) and content analysis (Merono-Cerdan, 2005). Chien-Ta Bruce Ho et al. (2009b), following Serrano-Cinca 2005's model using DEA and PCFA on 32 Taiwan banks, dramatically expands the data size and differentiates between the cost-oriented and internet-orientated efficiencies of banks. The contribution of this paper is to compare and identify, for the first time, the value-relevance of website and revenue output efficiency performances of the top largest Arab banks using DEA and PCFA methodologies.

\section{CONCEPTUAL FRAMEWORK AND METHODOLOGIES}

DEA calculates a firm's efficiency by transforming inputs into outputs relative to other organizations that provide similar services and use similar resources. The Charnes, Cooper, Rhodes (1978) DEA model is used in this research. The advantage of this technique is that it directly compares the most efficient bank against one or a combination of other similar banks. The model assumes input orientation and constant returns to scale and therefore allows comparison of banks that may be considerably smaller or larger. Further, it does not require an assumption of a functional form relating to inputs and outputs. In addition, PCFA is used as a means of a data reduction technique. This provides a procedure to explore how much information can be extracted from the final DEA scores.

The objective of PCFA is starting from a set of observed variables to create a smaller set of independent variables that explain the correlations existing between the original variables. These new variables, the principal components, are, in general, not observed, but they tend to have a meaning. The PCFA transformation is given by:

$$
\mathbf{Y}^{\mathrm{T}}=\mathbf{X}^{\mathrm{T}} \mathbf{W}=\mathbf{V} \boldsymbol{\Sigma}^{\mathrm{T}}
$$

The matrix $\Sigma$ is an m-by-n diagonal matrix with non-negative real numbers on the diagonal and $\mathbf{W} \mathbf{\Sigma} \mathbf{V}^{\mathbf{T}}$ is the singular value decomposition of $\mathbf{X}$. The following explains the PCFA using matrix algebraic. For a data matrix, $\mathbf{X}^{\mathbf{T}}$, with zero empirical mean, each row represents a different repetition of the experiment, and each column gives the results from a particular probe. Given a set of points in Euclidean space, the first principal component (the eigenvector with the largest eigenvalue) corresponds to a line that passes through the mean and 
minimizes sum squared error with those points. The second principal component corresponds to the same concept after all correlation with the first principal component has been subtracted out from the points. Each eigenvalue indicates the portion of the variance that is correlated with each eigenvector. Thus, the sum of all the eigenvalues is equal to the sum squared distance of the points with their mean divided by the number of dimensions. PCFA essentially rotates the set of points around their mean in order to align with the first few principal components. This moves as much of the variance as possible (using a linear transformation) into the first few dimensions. The values in the remaining dimensions, therefore, tend to be highly correlated and may be dropped with minimal loss of information. PCFA is the simplest of the true eigenvector-based multivariate analyses. PCFA is closely related to factor analysis and some statistical packages deliberately conflate the two techniques. True factor analysis makes different assumptions about the underlying structure and solves eigenvectors of a slightly different matrix. Principal components analysis differs from factor analysis in that there is no reduction in the number of variables after the transformation (Joliffe, 2002).

\section{DATA}

This research examines the bank's function as a financial intermediary between customers who deposit funds and those who borrow funds. In order to create the efficiency measures, a data set is created. The financial data are extracted carefully from individual banks' 2008 annual reports using Bankscope. Additional data of website information was gathered from the recently created website tool, Alexa.com. This data bank provides a unique source of world web traffic, which includes the Middle East, unlike other network tools, such as Compete.com, Google Trends, Comscore, and Hitwise. This data of bank website traffic are used as a proxy for one of the comparative banks' output performance. The other is total revenue.

A descriptive statistical analysis was applied to the data set to gather information of the features of the data, such as distribution, reliability and correlations. The research is guided by the relevance, availability and accuracy of the data. Homogeneity of data is essential when comparing relative performances of banks in and between countries, as well as an important requirement for the DEA model. These environmental differences are an obvious concern (Lozano-Vivas, 2001). Therefore all data are converted to US dollars at the $31^{\text {st }}$ December 2008 exchange rate and divided by respective individual annual inflation rates. This normalizes the data for statistical comparisons. Internet (2010) provides the source for the ranks of tracking numbers of website visits for December 2008 and Oanda (2009) provides the U.S. dollar foreign "buying" exchange rates and Coutsoukis (2008) for annual inflation rates.

Further consideration is the selection of inputs and outputs that enter the specification. There is no consensus as to the explicit definition and measurement of banks' inputs and outputs. Generally, each definition of input and output carries with it a particular set of banking concepts which influence and limit the analysis of the production characteristics of the industry. Ideally, all inputs and outputs should be accounted for, but in practice, typically a selection of asset outputs and liability inputs are dictated by data availability. This study of Arab banks uses three 'input' variables to create the efficiency frontier: 1) total deposits and short-term funding remittances released, 2) overhead operation cost (including operation expenses, excluding non-operation income, expenses, interest or loss) and personnel expenses, and 3) total assets. Revenue from operation by the firm's income statement and the ranking of average daily rate of website traffic of each bank are the two 'output' variables. The rank is calculated using a combination of "average daily visitors" to the bank's website and "page views" on the banks website over the past three months. The site with the highest combination of visitors and page views is ranked number one.

Despite these banks being selected for representing the top largest Arab banks by total assets, complete data were not easily accessible or transparent. Generally banks in Libya, Syria, Tunisia, and Morocco proved most difficult, if not impossible, to access both banking data and electronic website tracking. In addition, although every effort was made to collect unconsolidated annual reports of the individual banks, in some cases, consolidated reports were the only data available. Finally, though all banks are largely compliant with International Accounting Standards (IAS), consistent interpretation and uniform measurements of some annual reports between Islamic and non-Islamic banks proved difficult. 
Table 1: Descriptive Statistics of Top (62) Arab Banks, 2008

\begin{tabular}{lccccc}
\hline & Alexa Traffic Rank & Net Interest Revenue & Total Assets & Overheads & Deposits \\
\hline & $(\mathbf{1})$ & $(\mathbf{2})$ & $(\mathbf{A})$ & $(\mathbf{B})$ & $(\mathbf{C})$ \\
\hline Mean & $2,006,799.47$ & 365.06 & $14,228.85$ & 199.40 & $11,304.38$ \\
Standard Error & $508,834.68$ & 51.72 & $1,782.17$ & 28.91 & $1,435.41$ \\
Median & $538,020.00$ & 223.29 & $8,464.27$ & 131.59 & $6,807.18$ \\
Standard Deviation & $4,006,568.29$ & 407.28 & $14,032.84$ & 227.62 & $11,302.47$ \\
Kurtosis & 20.08 & 4.04 & 0.56 & 9.96 & 0.96 \\
Skewness & 4.00 & 1.92 & 1.21 & 2.72 & 1.29 \\
Range & $25,666,105.00$ & $2,022.65$ & $56,095.79$ & $1,328.80$ & $47,036.44$ \\
Minimum & $1,280.00$ & 0.29 & $1,081.51$ & 12.30 & 539.90 \\
Maximum & $25,667,385.00$ & $2,022.94$ & $57,177.30$ & $1,341.10$ & $47,576.34$ \\
Sum & $124,421,567.00$ & $22,633.90$ & $882,188.80$ & $12,363.04$ & $700,871.81$ \\
Count & 62 & 62 & 62 & 62 & 62 \\
\hline
\end{tabular}

Table 1 shows the descriptive statistics of 62 top Arab banks for 2008. The non-parametric Spearman's rho and Kendall's tau correlation tests were performed between the ranking of average daily rate of website traffic of each bank and the characteristics of banks - net interest revenue, total assets, total deposits, and overhead. Pearson's correlation matrix was not used as non-parametric data are included since the results of Pearson's correlation would be unduly influenced by outliers, unequal variances, non-normality and non-linearity. The data for monitoring web traffic, the proxy for internet banking, is ordinal data. Interpreting the web traffic non-parametric data is important. The lower the number, the higher the ranking and the greater the traffic volume. A negative correlation is therefore expected as ranking number falls (web traffic volume increases), revenue increases. It should also be noted that the magnitude for Spearman's rho is higher than Kendall's tau, even though conclusions are similar (Nelsen, 2007).

All results indicated negative correlation significant at the 0.01 level (2-tailed) with web traffic. Kendall's tau correlation between the two outputs' website traffic and revenue is negative (-0.49). Spearman's Rho is -0.67 . The rationalization of this finding is that the variances of revenue may be explained by the variance of web traffic; that is, that banks that have high ranking web traffic volume result in high revenue. However, the objective of this research is to measure the 'efficiency' of banks' output performance of producing high web traffic via internet banking and whether banks are efficient or not at generating high revenue. In other words, are there any observable differences in efficiencies of the two outputs?

To further analyze and empirically investigate the research questions, and to lessen the heterogeneous nature of the data used in this research, the 62-bank sample is divided into two equal groups of 31 banks. The median value (8,696.37 million USD) identifies the value below which 50 percent of the cases fall; i.e., the value of the total assets that divides this sample in half. Tables 2 and Table 3 illustrate the descriptive statistics of the categories of the specifications for small and big banks, respectively. Note that column (1) Alexa Traffic Rank identifies the rank order and not the frequency of traffic; hence, the lower the digit, the more popular the website.

Table 2: Descriptive Statistics of Top Arab Small Banks (31)

\begin{tabular}{|c|c|c|c|c|c|}
\hline & Alexa Traffic Rank & Net Interest Revenue & Total Assets & Overheads & Deposits \\
\hline & (1) & (2) & (A) & (B) & (C) \\
\hline Mean & $1,238,108.26$ & 631.40 & $24,757.35$ & 329.27 & $19,769.45$ \\
\hline Standard Error & $825,053.87$ & 77.48 & $2,324.23$ & 46.82 & $1,876.31$ \\
\hline Median & $113,075.00$ & 423.46 & $20,680.02$ & 253.33 & $16,659.32$ \\
\hline Standard Deviation & $4,593,705.52$ & 431.37 & $12,940.76$ & 260.71 & $10,446.83$ \\
\hline Kurtosis & 29.25 & 2.19 & -0.41 & 6.65 & 0.07 \\
\hline Skewness & 5.35 & 1.47 & 0.69 & 2.26 & 0.89 \\
\hline Range & $25,666,105.00$ & $1,834.98$ & $48,480.93$ & $1,239.29$ & $40,738.43$ \\
\hline Minimum & $1,280.00$ & 187.96 & $8,696.37$ & 101.81 & $6,837.91$ \\
\hline Maximum & $25,667,385.00$ & $2,022.94$ & $57,177.30$ & $1,341.10$ & $47,576.34$ \\
\hline Sum & $38,381,356.00$ & $19,573.38$ & $767,477.81$ & $10,207.27$ & $612,852.91$ \\
\hline Count & 31 & 31 & 31 & 31 & 31 \\
\hline
\end{tabular}


Table 3: Descriptive Statistics of Top Arab Big Banks (31)

\begin{tabular}{lccccc}
\hline & Alexa Traffic Rank & Net Interest Revenue & Total Assets & Overheads & Deposits \\
\hline & $(\mathbf{1})$ & $\mathbf{( 2 )}$ & $(\mathbf{A})$ & $\mathbf{( B )}$ & $(\mathbf{C})$ \\
\hline Mean & $2,775,490.68$ & 98.73 & $3,700.35$ & 69.54 & $2,839.32$ \\
Standard Error & $576,892.96$ & 12.18 & 352.56 & 9.03 & 285.20 \\
Median & $1,282,171.00$ & 90.63 & $3,327.19$ & 51.48 & $2,423.07$ \\
Standard Deviation & $3,212,004.06$ & 67.81 & $1,962.98$ & 50.26 & $1,587.93$ \\
Kurtosis & 1.23 & 2.45 & 0.19 & 0.96 & 0.30 \\
Skewness & 1.47 & 1.24 & 0.96 & 1.24 & 0.95 \\
Range & $11,026,488.00$ & 317.99 & $7,150.65$ & 191.79 & $6,236.55$ \\
Minimum & $68,630.00$ & 0.29 & $1,081.51$ & 12.30 & 539.90 \\
Maximum & $11,095,118.00$ & 318.28 & $8,232.16$ & 204.09 & $6,776.45$ \\
Sum & $86,040,211.00$ & $3,060.52$ & $114,710.99$ & $2,155.77$ & $88,018.90$ \\
Count & 31.00 & 31.00 & 31.00 & 31.00 & 31.00 \\
\hline
\end{tabular}

Validity tests - ANOVA and Median - are carried out. The ANOVA assumes that the underlying distribution is normal and compares the samples on the basis of the 'within' group and between group variation inefficiency. It tests whether the means of a population are the same (the null hypothesis) or if they differ between the populations (research hypothesis) by looking at the variances. The Median Test compares the two sample distributions of efficiency on the basis of their central tendency, as measured by the median; in all cases, the null hypotheses are rejected.

\section{ANALYSIS AND RESULTS}

Each data set initially follows validation tests, DEA and PCFA procedures. Using DEAP software - Coelli (1996) and Coelli, et al (1998) - data are carefully inputted to derive the comparative technical efficiency scores of the 62 individual banks' production functions using 21 different specification models. Technical efficiency measures the ability of banks to minimize costs and maximize revenues through the optimal use and distribution of resources, which assumes that the bank is operating on the industry's efficient frontier.

The DEA score ranking varies from 100 (highest efficiency ranking) to 0 (minimum efficiency). Hypothesis is tested for technical efficiency measure using the analysis of variance (ANOVA), Median Test and Wilcoxon Test. Confirmation of these tests implied that it is appropriate to construct production frontiers by pooling this data. Results show clear disparities between Arab banks' efficiency performances (the first research question). In addition, the most efficient banks are not necessary the largest. The Bank of Sharjah (UAE), Rakbank (UAE), and Invest Bank (UAE) are relatively small banks, yet overall, they have each scored many (from the 21 different specifications which are tested) very high efficiency results compared to the larger banks. Other banks with slightly lesser, but nevertheless impressive efficiency results, are Samba Financial Group (Saudi Arabia) and United Gulf Bank (UAE). All data results are available on request.

The next stage of the analysis is to extract and interpret the more relevant information from these DEA specifications, using PCFA. It is possible that a variable included in the specification of the model may or may not contribute to the calculation of efficiency, and vice versa. Using PASW Version 18 (formally SPSS), PCFA and validity tests are carried out on DEA scores of 62 banks' data results. The scores of the Component Matrix are then examined to identify coefficients above 0.40 showing which factor component can be identified by a cluster of high coefficient models. Some of the 21 different specifications derived substantial loadings in more than one factor. This is referred to as a 'complex' meaning, which means they have a relationship with two or more of the derived factors. Generally the factor with the highest loading is recognized. These component scores are plotted on Figure 1 and show a simple mapping of the coordinates. A, B and C represent the inputs - total assets, overheads and deposits, respectively. Output variables - website traffic and revenue - are represented by 1 and 2, respectively. All models are loaded with a positive sign on the first component. The highest weight is associated with the near complete models $12 \mathrm{AB}, 12 \mathrm{AC}$ and $12 \mathrm{~A}$, followed by models with only one output specification - internet traffic (1). It is apparent that three distinct clusters of models can be identified - those with only website traffic (1), those with only revenue output (2), and those with both (1) and (2). These results are supported by Serrano-Cinca et. al. (2003) 
and Chien-Ta Bruce Ho and Wu (2009a). When interpreting the second principal component, traditionally both the signs and the sizes of the loadings are considered. Again, results concur with both Serrano-Cinca et al. (2003) and Chien-Ta et al. (2009a)'s papers. Those with a negative signed coefficient are those which contain only the internet traffic (1) output. Those with a positive sign are revenue (2) output. Models that contain both outputs in their specification are associated with negligible loadings in the second component. The third component contains only two high coefficients (12B and $2 \mathrm{~B}$ ) - both positive and both identifying only overhead costs input (B). According to Serrano-Cinca et al. (2003), this component can be interpreted as cost efficiency.

By graphing the component matrix CP1 and CP2 results, the features of individual banks' efficiency scores under each relevant model reveal a pattern. The models of the outputs - 'internet' orientation (1) and 'revenue' orientation (2) - are clearly depicted. The combination of both output variables (12) follow the horizontal axis. The next step is to interpret these data results and identify from these different clusters of models, potential valuable information about which banks are comparatively efficient at generating website visits, revenue output, or both, ceteris paribus. Results can provide valuable information for policy implications of banks' present and future intended direction of efficiency output performances toward the value-relevance of internet banking.

Figure 1: PCFA Component Matrix of All Top (62) Arab Banks

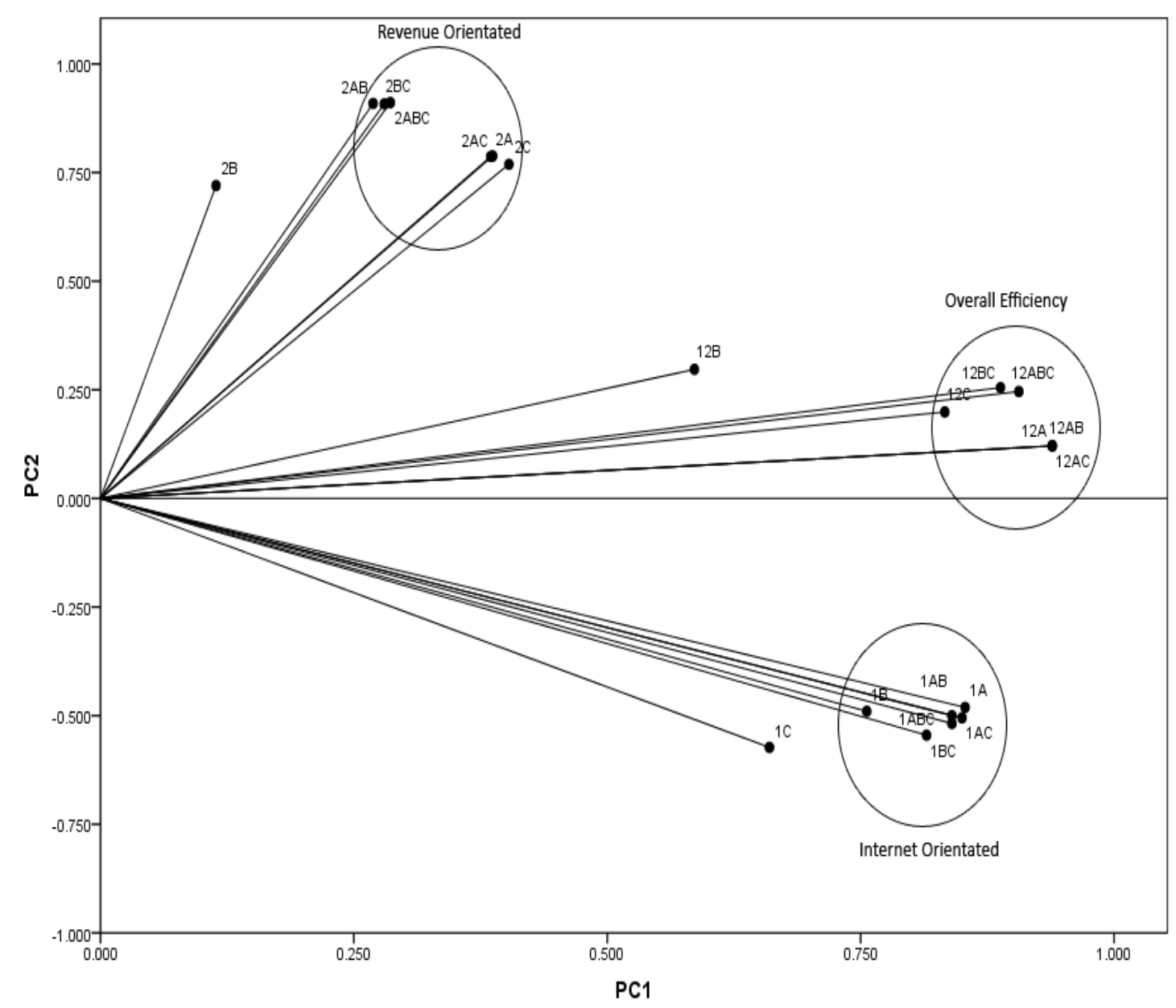


Results of efficiency scores of specification models $1 \mathrm{ABC}$ and $2 \mathrm{ABC}$ from the DEA are then used as coordinates to map the comparative efficiency results of all 62 banks. On the $\mathrm{x}$-axis is internet-orientated (internet traffic) model $(1 \mathrm{ABC})$ and on the y-axis is the revenue-orientated model $(2 \mathrm{ABC})$. A bivariate plot relationship between the two variables is shown in Figure 2. It reveals the comparative efficiency performances of those banks' outputs, which specifically skew towards the 'revenue' orientation, and those that skew more towards web traffic/internet orientation. The closer to the top of the scales on both axes, the more efficient the bank is in using the combination of their inputs $\mathrm{ABC}$ (assets, operation costs and deposits) to gain a more comparatively efficient revenue, web traffic or both-orientated output performance.

Examples of the very high DEA scoring banks which orientate towards greater 'revenue output efficiency' banks are Al Rajhi Bank (Saudi Arabia) and Commercial Bank of Kuwait (Kuwait). The bank that scores the highest DEA result for 'internet orientation output' is United Gulf Bank (Bahrain) at the bottom right corner. Those banks, such as Sharjah Islamic Bank (UAE) and The Housing Bank for Trade and Finance (Jordan), that are close to the diagonal line are orientating towards a combination of both 'overall efficiency' output. Most of the 62 banks cluster around the revenue-orientated output performance between 40-60 percent comparative efficiency scoring. These banks are efficient at generating revenues and not as comparatively efficient at generating web traffic for internet banking business. The overlapping of these banks is identified by the concentration of so many banks in one area, as illustrated in Figure 2.

Figure 2: DEA Scores of All (62) Top Arab Banks

\section{DEA Scores of 62 Top Arab Banks}

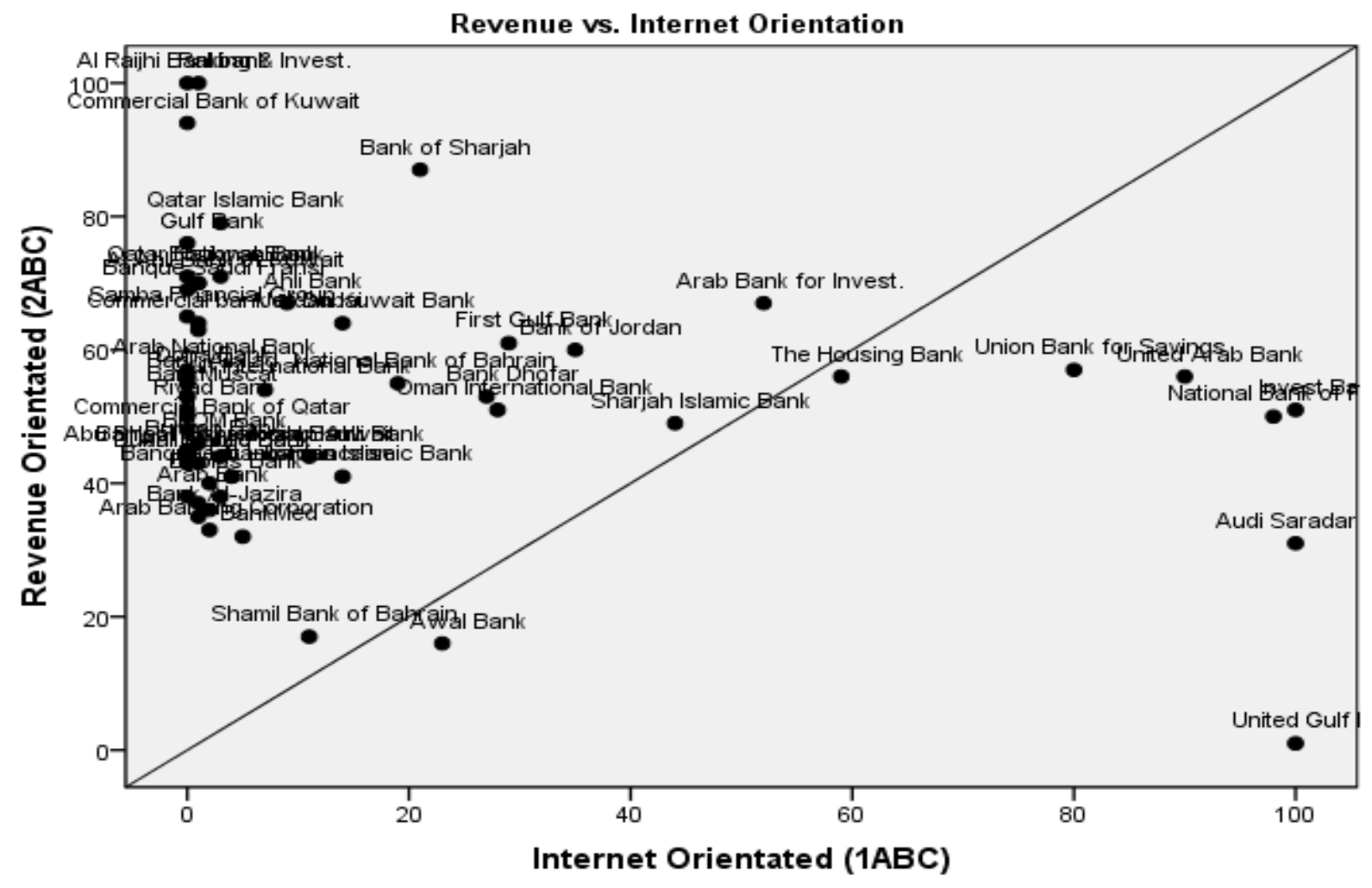

Despite the world recession of the Global Financial Crisis of 2008, top Arab banks generally continued to make pre-tax profits, albeit, at a lower percentage increase. By selecting the highest $15 \mathrm{DEA}$ 'internet'-orientated scoring banks from the total of 62 banks, an even clearer detailed investigation of these more efficient banks' comparative size, profitability and internet web traffic output efficiency can be identified and interpreted. 
Figure 3 shows the highest 15 DEA scores for web traffic-orientated banks and their corresponding pre-tax profit percentage change for 2008. With the exception of Invest Bank (UAE) and the Commercial Bank of Kuwait, all other banks increased their profit margins in 2008. Interestingly, banks, such as First Gulf Bank or Qatar Islamic Bank, that were profitable in 2008 were not as comparatively efficient. This may suggest that profits gained were not the result of performance efficiency but local market monopoly. In contrast, Rakbank from the UAE, attains a very high DEA score and comparatively high percentage pre-tax profit increase.

The comparative size of each bank is measured by total assets. The largest bank in this sample is the National Commercial Bank from Saudi Arabia, with 57.177 billion USD, and the smallest bank is the Union Bank for Savings and Investment in Jordon, with 1.081 billion USD. Plotting the DEA comparative efficiency scores from the $12 \mathrm{ABC}$ model against total asset values identifies whether large banks are comparatively more efficient than smaller banks. Note that the DEA uses constant returns to scale model, which theoretically allows for the comparison of large and small DMUs' efficiency performances (Charnes et al., 1978). Figure 4 compares 62 banks' total assets with their respective DEA efficiency scores for 2008. The resulting dispersion of the points on the graph illustrate that smaller banks, by total assets, attain a comparatively higher efficiency score. This is seen by the greater number of smaller banks in the lower right quadrant. Many smaller banks (those below the total asset meanvalue of 14.288 billion USD), such as the Bank of Sharjah (UAE), Invest Bank (UAE), the National Bank of Fujairah (UAE), Rakbank, (UAE), and the United Gulf Bank (Bahrain), have all scored 100 percent comparative efficiency. The larger banks, such as Arab Bank (Jordan), National Bank of Kuwait (Kuwait), National Commercial Bank (Saudi Arabia), and Riyadh Bank (Saudi Arabia), scored comparatively lower efficiency performances, less than the DEA mean value of 62.9 percent. Banks that are comparatively efficient are not necessarily big banks.

Figure 3: Annual Percentage Changes of Pre-tax Profits of the15 Highest DEA Scoring Banks

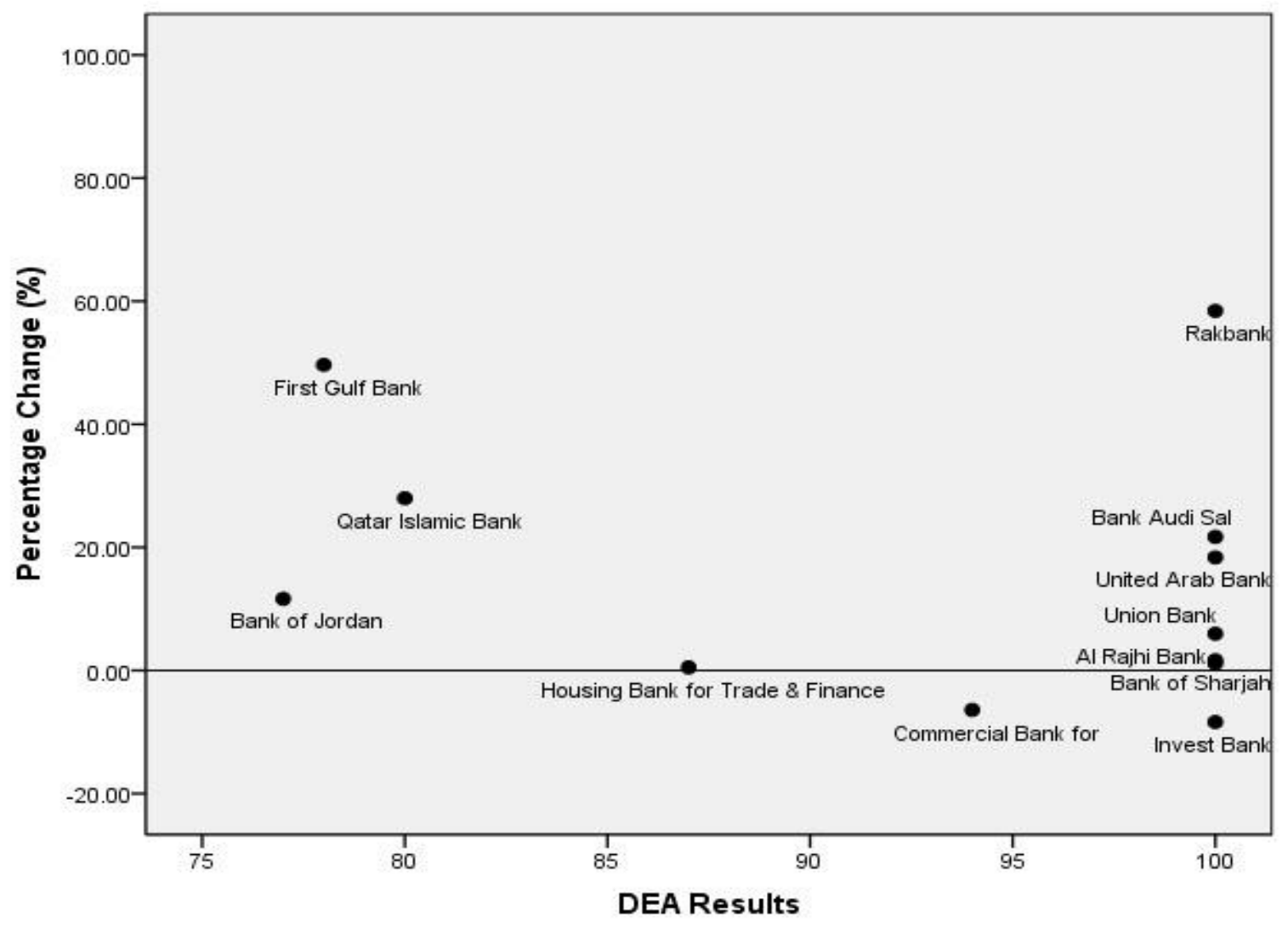


Figure 4: 62 Banks by Total Assets and DEA Scores, 2008

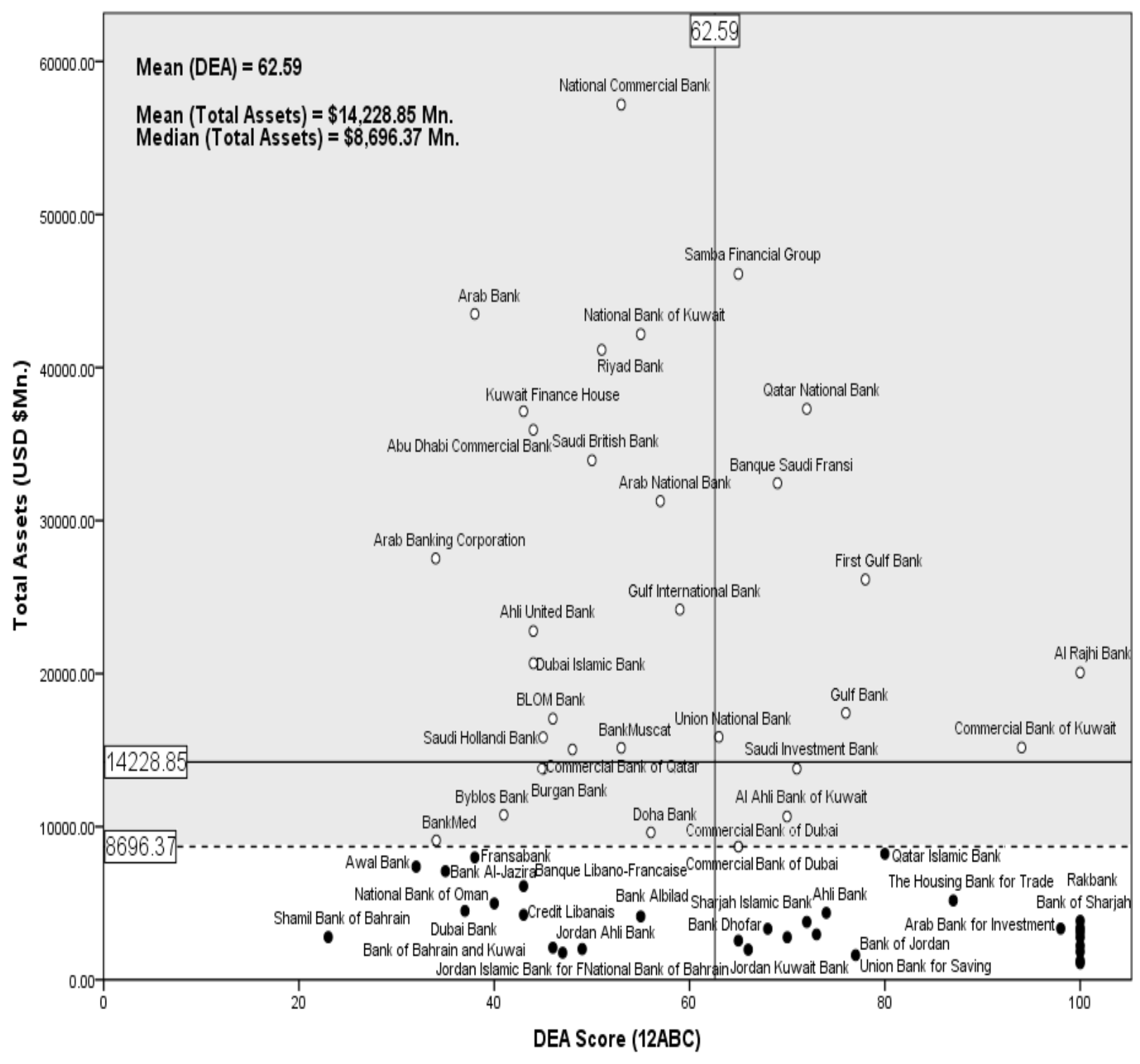

The concluding steps of this analysis are to repeat the PCFA for each of the two separate big and small bank samples. Similar to the full 62-bank sample, features of the models are revealed - those that orientate towards revenue, internet traffic and overall efficiency outputs. This is seen in Figure 5 for the big banks and Figure 6 for the smaller banks. The National Commercial Bank (Saudi Arabia) is the largest bank by total assets, but with only a 53 percent efficiency score compared to First Gulf Bank (UAE), which is approximately half its size by total assets, with a 100 percent efficiency score. Results show the 31 large banks to be evenly dispersed between high/low DEA scores and small/large total assets. The First Gulf Bank (UAE) and Al Rajhi Banking \& Investment Corp. (Saudi Arabia) scored 100 percent DEA efficiency performance. 
Figure 5: Top Arab (31) Big Banks by Total Assets and DEA Scores (12ABC)

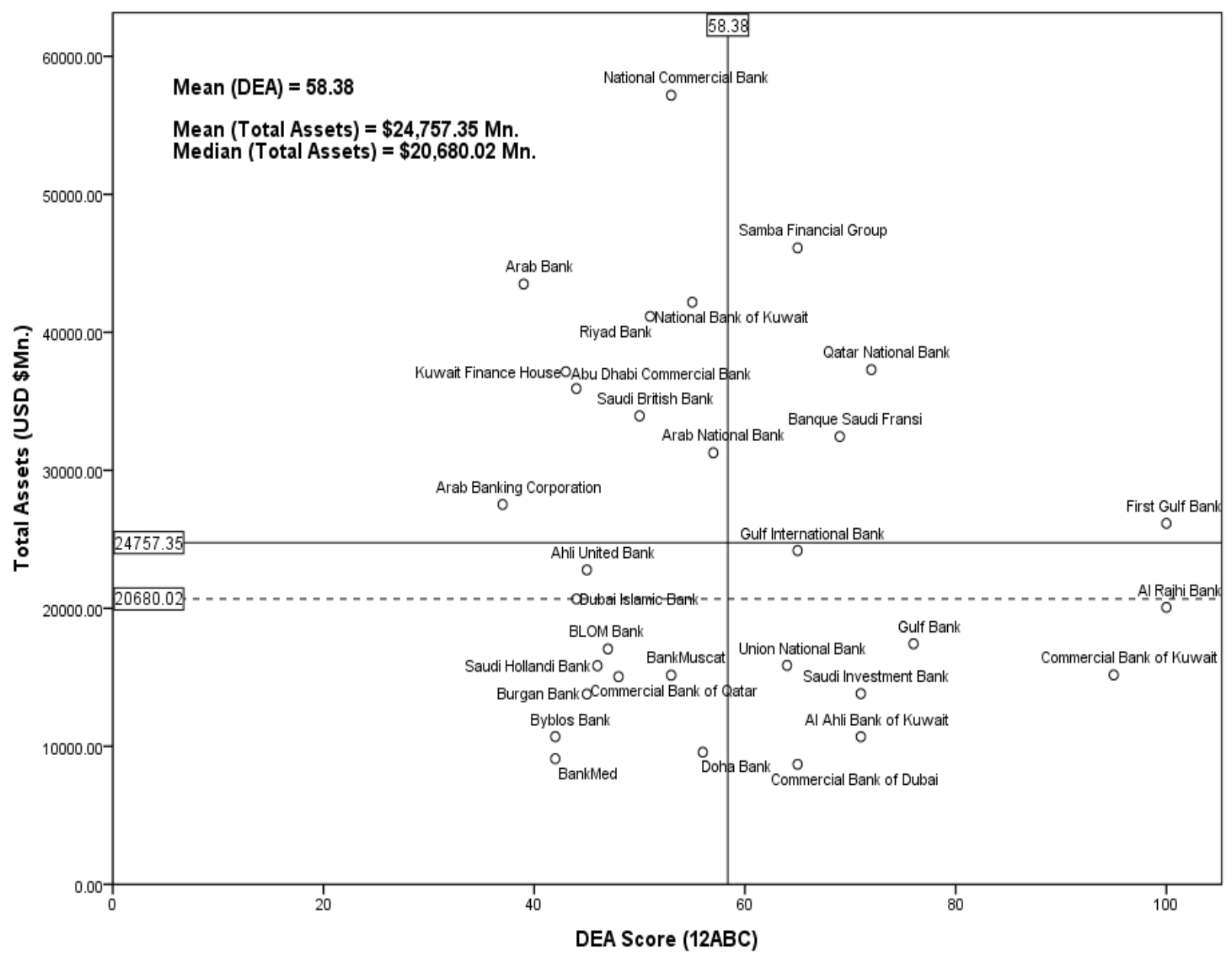

Four of the 31 smaller banks in Table 6 attain 100 percent DEA score - Bank Audi Sal (Lebanon), Fransabank (Lebanon), Invest Bank (UAE), National Bank of Fujairah (UAE), and the United Gulf Bank (Bahrain). The 31 smaller banks clearly show that comparatively smaller banks perform more efficiently than the comparatively bigger banks. Examples of such banks are: the United Gulf Bank, Invest Bank, United Arab Bank and United Gulf Bank, for example. It is now possible to test the null hypothesis that there is no difference between big and small banks' DEA scores. The correlation coefficient results for the Kendall's Tau and Spearman's Rho are negative and not significantly differently from zero; that is, the null hypothesis is rejected.

To identify which individual banks are efficient banks at internet web traffic-orientation and revenue orientation, the values of the specifications $1 \mathrm{ABC}$ and 2ABC DEA models for the big banks are plotted on Figure 7. Only the "First Gulf Bank" shows high efficiency scores for generating internet web and revenue outputs. The remaining other 30 big banks show surprisingly low DEA scores for revenue orientation. 
Figure 6: Top Arab (31) Small Banks by Total Assets and DEA Scores (12ABC)

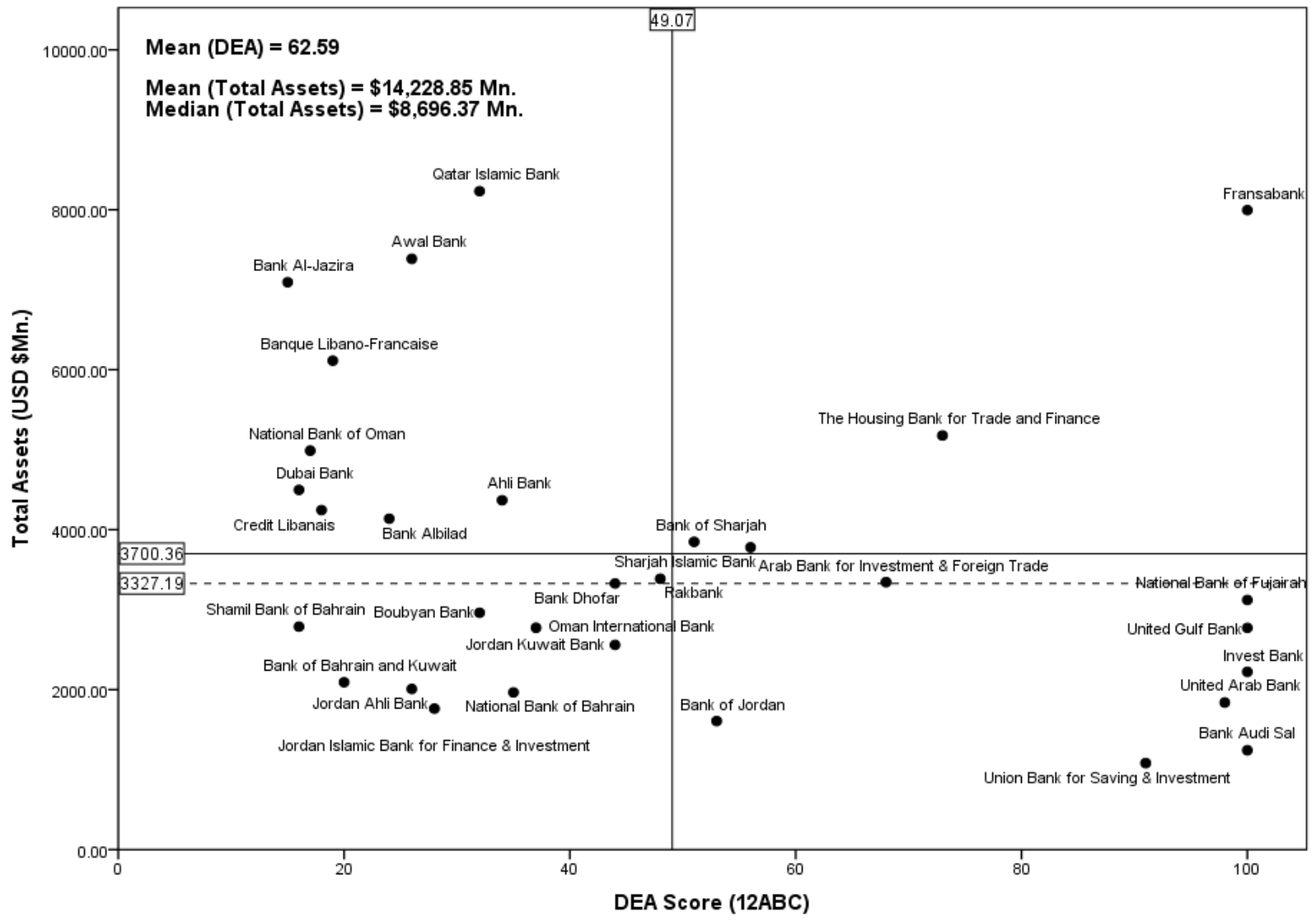

Figure 7: Dispersion of Big Banks' DEA Scores for 2ABC and 1ABC Specifications

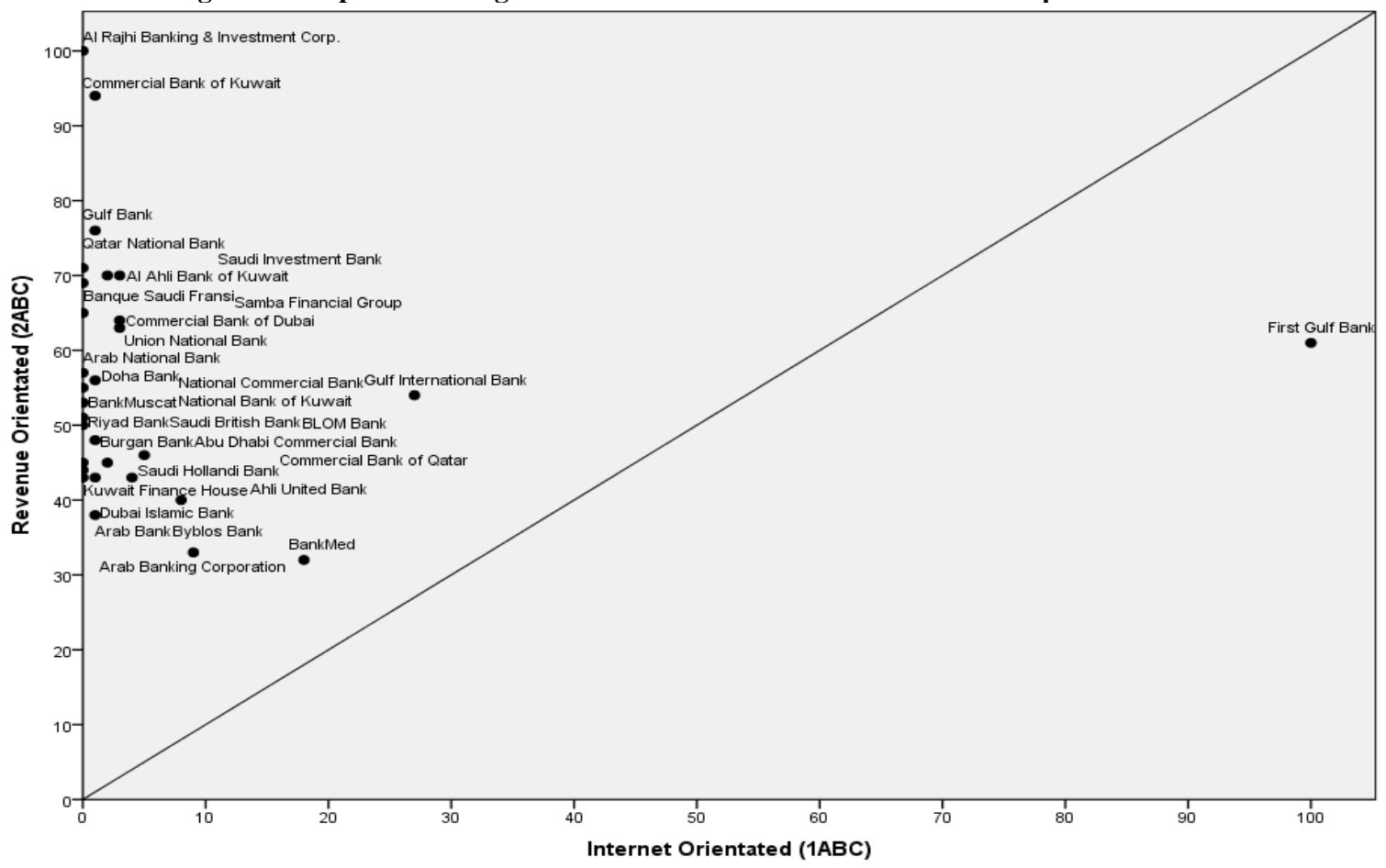


To identify which individual banks are efficient banks at internet web traffic orientation and revenue orientation, the values of the specifications $1 \mathrm{ABC}$ and 2ABC DEA models for the big banks are plotted on Figure 7. Only the "First Gulf Bank" shows high efficiency scores for generating internet web and revenue outputs. The remaining other 30 big banks show surprisingly low DEA scores for revenue orientation.

Similar to Figure 7, the results for small banks are shown on Figure 8. A more distinct pattern is observed. The sample is almost completely divided in half, with most of these smaller banks, such as Invest Bank and United Gulf Bank, achieving higher efficiency values for internet-orientation rather than revenue. Fransabank achieved the highest efficiency score for revenue orientation.

The Kendall's tau and Spearman's rho's correlation coefficients of the DEA scores of 1ABC and 2ABC results are negative and not significantly different from zero. (Pearson's rho $=-0.254$ and $\mathrm{p}$-value $=0.167$. Kendall's tau $=-0.103$ with a p-value $=0.432$ ). This would imply that there is no observable relationship between web traffic and revenue. Similar to the larger banks' analyses, significant differences between web traffic and revenue cannot be found in these small bank results. Serrano-Cinca et al. (2005), in analyzing internet companies, used the Pearson's correlation for the two models and obtained a coefficient of -0.014 which was not significant from zero. Though there is a close non-zero correlation between revenues web traffic and revenues, this should not be interpreted to mean that banks that are efficient at achieving internet traffic are also efficient at achieving revenues. All firms may be efficient, but they are not equal in terms of the way in which efficiency is generated. In other words, some banks may be more efficient at generating web traffic output than generating revenue output.

Figure 8: Dispersion of Small Banks' DEA Scores for 2ABC and 1ABC Specifications

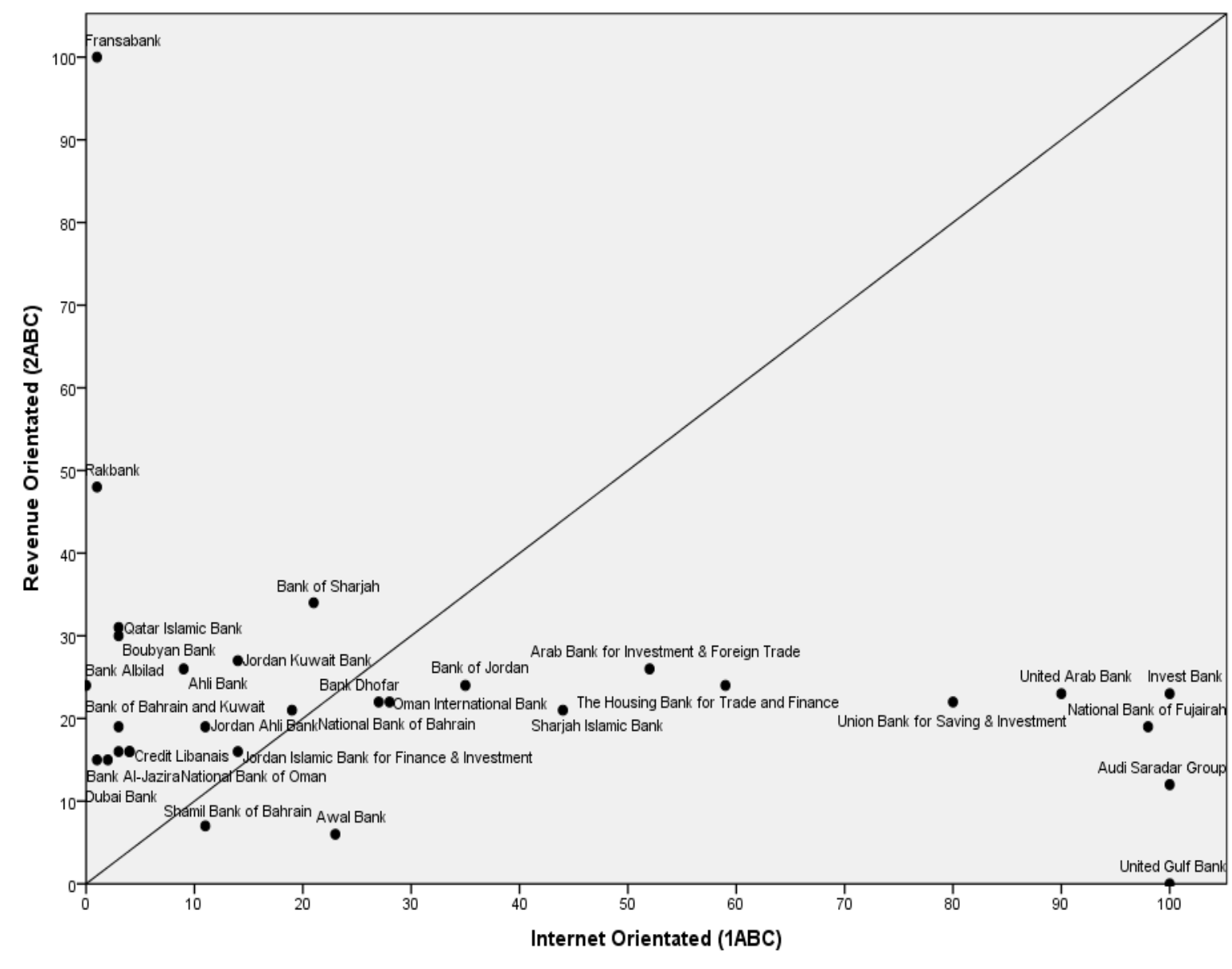




\section{DISCUSSION AND CONCLUDING OBSERVATIONS}

The objective of this research has been to provide a methodology that considers the value-relevance of internet web traffic and revenue to highlight the importance of 'best practices' associated with efficiency performances in the banking industry of the Arab world. Results show that disparities do exist between comparative efficiency performances of these top Arab banks. The highest DEA-scoring bank for 'internet orientation output' is the United Gulf Bank (Bahrain). This bank is the smallest by total assets from the sample. Clearly, size does not always count when considering comparative efficiency performances of those banks that are more internetorientated. Those banks, such as Sharjah Islamic Bank (UAE) and The Housing Bank for Trade and Finance (Jordan), achieved the highest DEA scores for comparative 'overall efficiency' output. Most of the 62 banks clustered around the revenue-orientated output performance scored between 40 and 60 percent comparative efficiency. These banks are efficient at generating revenues and not as comparatively efficient at generating web traffic. Of these banks, the larger banks (by total assets or profitability) were not always technically more efficient than the smaller ones. This is highlighted by the performances of Invest Bank (UAE), Al Rajhi Bank (Saudi Arabia) and Qatar Islamic Bank (Qatar), for example.

This empirical study has both theoretical and practical significance. Theoretically, this is the first study conducted to include data of Arab bank internet traffic to measure productivity performance. On a practical level, this study contributes to research knowledge by collecting, collating and measuring electronic data that has only recently been available. Clarity and insight into banking productivity efficiency will contribute to future competition within the Arab world. On a micro level, this research highlights the interest and growing participation of internet banking within the MENA region banking industry. On a macro level, instilled by the impetus of World Trade Organisation (WTO) policy agreement on the liberalization of financial services, it exposes, albeit on a small scale, the state of electronic data availability and transparency in the MENA region. From a policy perspective, this study supports the importance of considering the value-relevance of internet web traffic when measuring comparative technical efficiency throughout the banking industry in the Arab world.

\section{AUTHOR INFORMATION}

Dr. Bruce Q. Budd has teaching experience at Graduate and Post-graduate levels at universities in many countries: U.K., Australia, Hong Kong, UAE. and Saudi Arabia. Professional experience in industry. Research interests in economics, finance and banking, particularly in areas of efficiency performances and financial and capital markets.

Daniel B. Budd is a graduate of Edith Cowan University and the University of Western Australia. Previous industrial experience in web development of eCommerce solutions and marketing. His research specialisation area is electronic business information systems.

\section{REFERENCES}

1. Al-Faraj, T., Alidi, A., and Bu-Bshait, K. . (1993). Evaluation of bank branches by means of data envelopment analysis. International Journal of Operations and Production Management 13, 45-52.

2. Al-Shammari, M. A. S., A. . (1998). Modeling the operational efficiency of banks: a nonparametric methodology. Logistics Information Management 11, 5-12.

3. Berger, A. N., \& Humphrey, D. B. (1997). Efficiency of Financial Institutions: International Survey and Directions for Future Research. European Journal of Operational Research, 98, 175-212.

4. Berger, A. N., Hunter, W. C., \& Timme, S. G. (1993). The Efficiency of Financial Institutions: A Review of Reserach Past, Present and Future. Journal of Banking and Finance, 17, 221-249.

5. Berger, A. N., \& Mester, L. J. (1997). Inside the Black Box: What Explains Differences in the Efficiencies of Financial Institutions? Journal of Banking and Finance, 21, 895-947.

6. Chaffai, M. E. (1997). Estimating input-specific technical inefficiency: The case of the Tunisian banking industry. European Journal of Operational Research, 98(2), 314-331.

7. Charnes, A., Cooper, W. W., \& Rhodes, E. (1978). Measuring the Efficiency of Decision Making Units. European Journal of Operational Research, 2, 429 - 444. 
8. Chien-Ta Bruce, H. D. D., Wu;. (2009). Online banking performance evaluation using data envelopment analysis and principal component analysis. Journal of Computers and Operations Research, 36, 1835 1842.

9. $\quad$ Coelli, T. (1996). Guide to DEAP Version 2.1: A Data Envelopment Analysis (Computer) Program.

10. Coelli, T., Rao, D.S.P., and Battese, G.E. . (1998). An Introduction to Efficiency and Productivity Analysis.

11. Coutsoukis, P. (2008). Annual Inflation Rates. from http://www.photius.com/rankiings/economy/inflation_rate_2008

12. Daniel, E. (2000, November 3-4). Who Dares Wins? On-Line Banking Services and Innovation Types. Paper presented at the 9th Annual Business Information Technology Conference, Manchester, UK.

13. Gallaugher, M. A., P; BarNir, A;. (2001). Revenue streams and digital content providers: an empirical investigation. Journal of Information and Management, 38(7), 473-485.

14. Internet, A. (2010). The Web Information Company. 2010, from http://www.alexa.com

15. Jolliffe, I. T. (2002). Principle Component Analysis, 2nd Edition: Springer.

16. Lozano-Vivas, M. E. C. M. D. A. (2001). Technological and Environmental Differences in the European Banking Industries. Journal of Financial Services Research, 19(2), 147.

17. Mar-Molinero, C. S. (2003). Measuring DEA efficiency in Internet Companies. Journal of Financial Services Research, 38(4), 147.

18. Mar-Molinero, C. S. (2004). Selecting DEA Specifications and Ranking Units Via PCA. The Journal of the Operational Research Society, 55(5), 521-528.

19. Merono-Cerdan, A. L., Soto-Acosta, P.,. (2005). Examining e-business impact on firm performance through website analysis. International Journal of Electronic Business, 3(6), 583-598.

20. Min, M. a. (2005). Decision support models for the selection of internet access technologies in rural communities. Telematrics Informatics, 22(3), 2041-2219.

21. Mostafa, M. (2007). Benchmarking top Arab banks' efficiency through efficient frontier analysis. Industrial Management \& Data Systems, 107(6), 802-823.

22. Nelsen, G. A. F. a. R. B. (2007). On the relationship between Spearman's rho and Kendall's tau for pairs of continuous random variables. Journal of Statistical Planning and Inference, 137, 2143-2150.

23. Oanda. (2009). Oanda Currency Convertor. 2010, from http://www.oanda.com/currency/converter/

24. Owens, I., Robertson. D. (2000). Aligning c-Commerce with Business Strategy: The Case of the Bank of Scotland. Paper presented at the 5th UKAIS Conference, University of Wales Institute, Cardif, UK.

25. Seiford, L., and Zhu, J. (1999). Profitability and marketability of the top 55 US commercial banks. Management Sciences, 45, 1270-1288.

26. Serrano-Cinca, C. F.-C. n., Y. Mar-Molinero, C. . (2005). Measuring DEA Efficiency in internet companies. Decision Support Systems, 38, 557-573.

27. Shah, M. H. B., Rahat.H. (2002). A Decision Making Framework for Internet Banking Based on Critical Success Factors Approach. Paper presented at the Business Information Systems. Retrieved from http://bis.kie.ae.poznan.pl/biblio/

28. Statistics, I. W. (2008). Internet Usage in the Middle East: Middle East Internet Usage \& Population Statistics. Retrieved 25 May 2008, 2008, from http://www.internetworldstats.com/stats5.htm

29. Wen, H. J., Lim, B., Huang, H.L. . (2003). Measuring e-commerce analysis DEA approach. Industrial Management and Data Systems, 103(9), 703-710.

30. Wu, D., Yang, Z., Liang, L.,. (2006). Using DEA-neutral network approach to evaluate branch efficiency of a large Canadian bank. Expert Systems with Applications, 31(1), 108-115. 